\title{
PENGARUH IKLIM SEKOLAH TERHADAP KINERJA GURU DALAM PEMBELAJARAN MATEMATIKA DI UPT SEKOLAH DASAR NEGERI DI KECAMATAN SUKAMAJU
}

\author{
Syafruddin \\ Universitas Cokroaminoto Palopo ${ }^{1}$ \\ syafsukamaju@gmail.com ${ }^{1}$
}

\begin{abstract}
Abstrak
Iklim sekolah merupakan faktor penting mempengaruhi kinerja guru dalam menjalankan tugasnya karena iklim sekolah yang kondusif berpengaruh positif terhadap guru dalam menjalankan tugas.. Iklim sekolah yang baik akan berdampak positif terhadap kinerja guru dalam pembelajaran matematika di UPT sekolah dasar negeri di kecamatan sukamajuPenelitian ini merupakan penelitian ex-post facto yang bertujuan untuk mengetahui (1) deskripsi iklim sekolah di UPT Sekolah Dasar Negeri di kecamatan Sukamaju. (2) deskripsi kinerja guru dalam pembelajaran Matematika di UPT Sekolah Dasar Negeri di kecamatan Sukamaju, (3) pengaruh iklim sekolah terhadap Kinerja guru dalam pembelajaran Matematika di UPT Sekolah Dasar Negeri di kecamatan Sukamaju pada tahun pelajaran 2020/2021. Populasi dalam penelitian ini adalah guru di UPT Sekolah Dasar Negeri yang ada di Kecamatan Sukamaju Kabupaten Luwu Utara. Teknik pengambilan sampel adalah purposive sampling dengan pertimbangan kondisi sekolah yang di masa pandemi Covid-19, sehingga guru tidak selalu hadir di sekolah bersamaan setiap hari. Instrumen yang digunakan adalah kuesioner iklim sekolah, dan kuesioner kinerja guru dalam pembelajaran matematika. Hasil penelitian menjukkan (1) deskripsi iklim sekolah di UPT Sekolah Dasar Negeri di kecamatan Sukamaju berada pada kategori sedang. (2) deskripsi kinerja guru dalam pembelajaran Matematika di UPT Sekolah Dasar Negeri di kecamatan Sukamaju berada pada kategori sedang, (3) terdapat pengaruh yang signifikan iklim sekolah terhadap Kinerja guru dalam pembelajaran Matematika di UPT Sekolah Dasar Negeri di kecamatan Sukamaju.

Kata Kunci: Iklim Sekolah, Kinerja Guru
\end{abstract}

\section{A. Pendahuluan}

Pendidikan merupakan kebutuhan dasar manusia dalam menjalani kehidupan di dunia. Sebagai kholifah di muka bumi manusia dituntut memiliki banyak ilmu pengetahuan, karena dengan begitulah manusia akan akan mampu hidup layak serta mampu mengatur alam yang dibebankan Allah kepadanya. Sekolah sebagai lembaga penanggungjawab terlaksananya pendidikan mempunyai peran penting dalam memberikan layanan kepada masyarakat. Pelaksanaan tugas guru di sekolah semakin lama semakin berat sesuai dengan semakin komplitnya 
tuntutan masyarakat dalam mendapatan pendidikan yang lebih baik untuk generasi penerus bangsa ke depan

Berdasarkan Undang-undang Nomor 20 Tahun 2003 tentang Sistem Pendidikan Nasional Pasal 3 menyatakan bahwa:

Pendidikan Nasional berfungsi mengembangkan kemampuan dan membentuk watak serta peradaban bangsa yang bermartabat dalam rangka mencerdaskan kehidupan bangsa, bertujuan untuk berkembangnya potensi peserta didik agar menjadi manusia yang beriman, dan Bertakwa kepada Tuhan Yang Maha Esa, berakhlak mulia, sehat, berilmu, cakap, kreatif, mandiri, dan menjadi warga negara yang demokratis serta bertanggung jawab.

Tujuan pendidikan nasional tersebut akan tercapai dengan baik dipengaruhi oleh iklim sekolah yang baik, motivasi kerja pendidik dalam menjalankan tugas yang bagus dan kinerja guru yang meningkat.

Iklim sekolah yang baik memberikan pengaruh positif terhadap kinerja guru. Karena dengan iklim atau suasana lingkungan sekolah yang baik memberikan kenyamanan terhadap guru menjalankan tugas. Dukungan rasa nyaman guru dalam tugas akan muncul motivasi pada dirinya untuk bekerja secara profesional dan ikhlas tentunya akan memberikan sumbangsi kinerja yang baik pula dan kemungkinan besar memberikan efek positif terhadap kemajuan peserta didik dalam belajar, sehingga akan lahir siswa-siswa yang menjadi generasi masa depan bangsa yang handal.

Berdasarkan observasi awal penulis dengan mengamati keadaan dari beberapa sekolah, bahwa terkadang di sekolah muncul kelompok-kelompok yang mendukung dan yang kurang mendukung kebijakan kepala sekolah. Ada guru yang kurang senang dengan suasana iklim sekolah yang ada sehingga terkadang malas menjalankan tugas sebagai guru dengan baik. Ada juga guru yang senang dengan iklim atau suasana yang ada di sekolahnya, sehingga senang menjalankan tugasnya keseharian.

Terkadang guru dalam menjalankan tugasnya mengalami penurunan kualitas disebabkan beberapa faktor antara lain adalah iklim sekolah yang kurang mendukung dan motivasi kerja guru yang menurun. Jika iklim sekolah atau keadaan di lingkungan sekolah kurang mendukung terkadang guru kurang semangat dalam menjalankan tugasnya mengajar di sekolah. Sehingga perlu iklim sekolah yang 
kondusif yang dapat memberikan motivasi kerja guru dalam menjalankan tugasnya, agar guru bisa berinovasi, kreatif dan menarik bagi siswa dalam mengajar.

Iklim sekolah yang mendukung terciptanya motivasi kerja yang besar pada guru dapat mempengaruhi kinerja guru dalam menjalankan tugas. Sudah sering kita dengar atau amati di beberapa tempat ada guru yang terkadang tidak terlalu bergairah untuk ke sekolah dan motivasi dalam dirinya untuk melaksanakan kewajibannya sebagai guru terkadang diabaikan. Salah satu penyebabnya karena iklim sekolah terkadang kurang disenangi oleh guru dan alasan lain kurangnya motivasi dalam diri guru untuk menjalankan tugasnya sebagai guru.

Sesuai pendapat Castro dan Martins 2010 (dalam Werang 2018;14) mengartikan iklim organisasi sebagai persepsi perasaan dan sikap yang dimiliki anggota organisasi tentang aspek-aspek mendasar organisasi yang merefleksikan norma, nilai, dan sikap yang secara positif atau negatif berpengaruh terhadap prilaku setiap individu

Iklim organisasi yang dimaksud dalam penelitian ini tentunya iklim sekolah tempat dimana guru bekerja, baik berupa manusia maupun berupa sarana prasarana yang ada di lingkungan sekolah termasuk juga kepemimpinan seorang kepala sekolah.

Hoy dkk (dalam Werang dkk., 2016) mengemukaan dua dimensi interkasi interpersonal yang berkaitan dengan iklim organisasi (sekolah) yaitu (1). Prilaku kepemimpinan kepala sekolah yang mencakup empat hal yajni: (a). Allofness; merujuk kepada prilaku kepala sekolah yang dicirikan oleh sebuah relasi formal dan inpersonal; (b).production emphazis; merujuk kepada prilaku kepala sekolah dicirikan oleh supervisi yang menggunakan arahan-arahan dan perangkatperangkat komunikasi yang setereotip; (c). trust; merujuk kepada prilaku kepala sekolah dalam usaha nyata memajukan organisasi; dan (d). Consideration ; merujuk kepada prilaku kepala sekolah yang menjaga relasi manusiawi dengan guru-guru.

Dari penjelasan itu disimpulkan bahwa iklim sekolah bisa dari gaya kepemimpinan seorang kepala sekolah, dimana kepala sekolah yang seharusnya bisa menciptakan suasana sekolah yang kondusif agar semua warga sekolah merasa nyaman berada dan bekerja di lingkungan sekolah. Kepala sekolah harus mampu membuat iklim sekolah yang menyebabkan guru betah bekerja dan termotivasi di 
sekolah, yaitu dengan menjaga hubungan baik dengan semua warga sekolah dan menjadikan guru sebagai rekan kerja bukan sebagai bawahan dalam sebuah organisasi tetapi kolega atau kawan seprofesi yang mengharapkan dihargai hasil kerjanya oleh kepala sekolah.

Berdasarkan uraian latar belakang tersebut di atas, penulis bermaksud melakukan penelitian tentang Pengaruh Iklim Sekolah terhadap Kinerja Guru dalam pembelajaran matematika di UPT Sekolah Dasar Negeri di kecamatan Sukamaju Kabupaten Luwu Utara.

Permasalahan dari penelitian ini adalah sebagai berikut :(1). Bagaimanakah deskripsi iklim sekolah di UPT Sekolah Dasar Negeri di kecamatan Sukamaju. (2).Bagaimanakah deskripsi kinerja guru dalam pembelajaran Matematika di UPT Sekolah Dasar Negeri di kecamatan Sukamaju. (3). Apakah ada pengaruh iklim sekolah terhadap Kinerja guru dalam pembelajaran Matematika di UPT Sekolah Dasar Negeri di kecamatan Sukamaju?

Adapun tujuan dari penelitian ini adalah agar dapat: (1). Mendeskripsikan iklim sekolah di UPT Sekolah Dasar Negeri di kecamatan Sukamaju. (2).Mendeskripsikan kinerja guru dalam pembelajaran Matematika di UPT Sekolah Dasar Negeri di kecamatan Sukamaju. (3). Mengetahui pengaruh iklim sekolah terhadap Kinerja guru dalam pembelajaran Matematika di UPT Sekolah Dasar Negeri di kecamatan Sukamaju.

Manfaat yang diharapkan dari penelitian ini adalah: (1). Bagi guru, diharapkan dapat menjadi masukan dan pedoman dalam menjalankan tugas dan selalu termotivasi dalam bekerja. (2). Bagi UPT Sekolah Dasar, penelitin ini diharapkan memberikan masukan untuk terciptanya iklim sekolah yang lebih kondusif sehingga guru senang menjalankan tugasnya di sekolah.. (3). Bagi Dinas Pendidikan, sebagai bahan masukan dalam membuat kebijakan untuk menciptakan lingkungan sekolah yang iklimnya disenangi oleh semua warga sekolah. (4). Bagi peneliti, penelitian ini adalah sebagai temuan awal untuk terciptanya iklim sekolah yang kondusif dan motivasi kerja yang tinggi dalam meningkatkan kinerja guru pada instansi pendidikan. 


\section{B. Metode Penelitian}

Penelitian ini adalah penelitian Ex post Facto dengan menggunakan pendekatan kuantitatif untuk menemukan ada atau tidaknya pengaruh yang signifikan antara iklim sekolah dengan kinerja guru. Selanjutnya dicari langkahlangkah atau solusi yang relevan untuk meningkatkan kinerja guru.

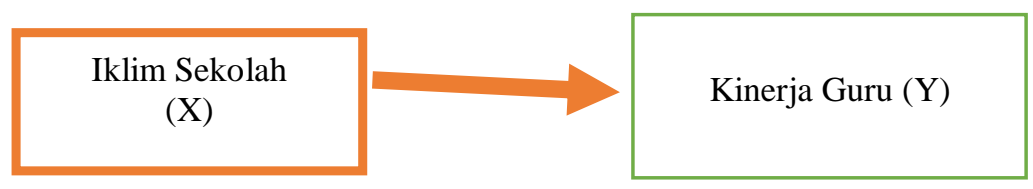

Gambar 1 Desain Penelitian

Penelitian ini dilaksanakan di UPT Sekolah Dasar Negeri Kecamatan Sukamaju Kabupaten Luwu Utara dan pelaksanaannya dimulai bulan Februari 2021 sampai dengan bulan Maret 2021 yang dimulai dari penyampaian surat izin dari Ketua Prodi Magister Pendidikan Matematika Universitas Cokroaminoto Palopo kepada Korwil Bidang Pendidikan Kecamatan Sukamaju dan kepala UPT Sekolah Dasar Negeri di Kecamatan Sukamaju Kabupaten Luwu Utara

Populasi dalam penelitian ini adalah seluruh guru di UPT Sekolah Dasar Negeri Kecamatan Sukamaju Kabupaten Luwu Utara. Penentuan sampel menurut Suharsini Arikunto bahwa apabila subyek kurang dari 100, maka lebih baik diambil semua. Namun karena populasinya lebih dari 100 orang guru, sehingga penelitiannya termasuk penelitian sampeling dengan jumlah guru di UPT Sekolah Dasar Negeri Kecamatan Sukamaju sebanyak 17 UPT Sekolah Dasar Negeri dengan jumlah guru 161 orang.

Sampel peneliti ingin menggunakan sistem Purposive sampling yaitu sampel ditentukan peneliti dari setiap sekolah berdasarkan kaadaan tertentu. Kelebihannya metode ini yaitu praktis karena sampel penelitian diketahui jumlahnya. Sampel yang diambil bisa memberikan gambaran yang jelas tentang ada atau tidaknya pengaruh iklim sekolah dan motivasi kerja terhadap kinerja guru di UPT Sekolah Dasar Negeri di kecamatan Sukamaju. Jadi peneliti memilih sebanyak 3 (tiga) orang guru perwakilan setiap sekolah. Sehingga dari 17 UPT SD Negeri di kecamatan Sukamaju didapat 51 guru yang menjadi sampel penelitian 


\section{Hasil dan Pembahasan}

\section{Hasil Penelitian}

Peneliti dalam melakukan pengolahan data hasil penelitian menggunakan bantuan aplikasi SPSS.

Analisis Deskriptif Variabel Penelitian

\begin{tabular}{llllllll}
\hline & $\begin{array}{l}\text { Ren- } \\
\text { tang }\end{array}$ & $\begin{array}{l}\text { Mini- } \\
\text { mum }\end{array}$ & $\begin{array}{l}\text { Maksi- } \\
\text { mum }\end{array}$ & Jumlah & Rata-rata & $\begin{array}{l}\text { Standar } \\
\text { Deviasi }\end{array}$ & Variansi \\
\hline Iklim sekolah & 42 & 75 & 117 & 4.883 & 95,75 & 10,151 & 103,034 \\
Kinerja Guru & 43 & 75 & 118 & 4.897 & 96,02 & 10,975 & 120,460 \\
\hline
\end{tabular}

Sumber data penelitian 2021

Data yang diperoleh dari angket variabel iklim sekolah teridir dari 30 item menyatakan beradasarkan penryataan. Disajikan hasil analisis statistika deskreptif Hasil analisis deskriptif iklim sekolah

\begin{tabular}{cc}
\hline Statistika Deskriptif & Nilai Statistik \\
\hline Rata-rata & 95,75 \\
Median & 96,00 \\
Modus & 94 \\
Standar Deviasi & 10,151 \\
Kurtosis & $-0,553$ \\
Skewness & $-0,116$ \\
Rentang & 42 \\
Minimum & 75 \\
Maksimum & 117 \\
Jumlah & 51 \\
\hline
\end{tabular}

Sumber : Hasil analisis data primer (2021)

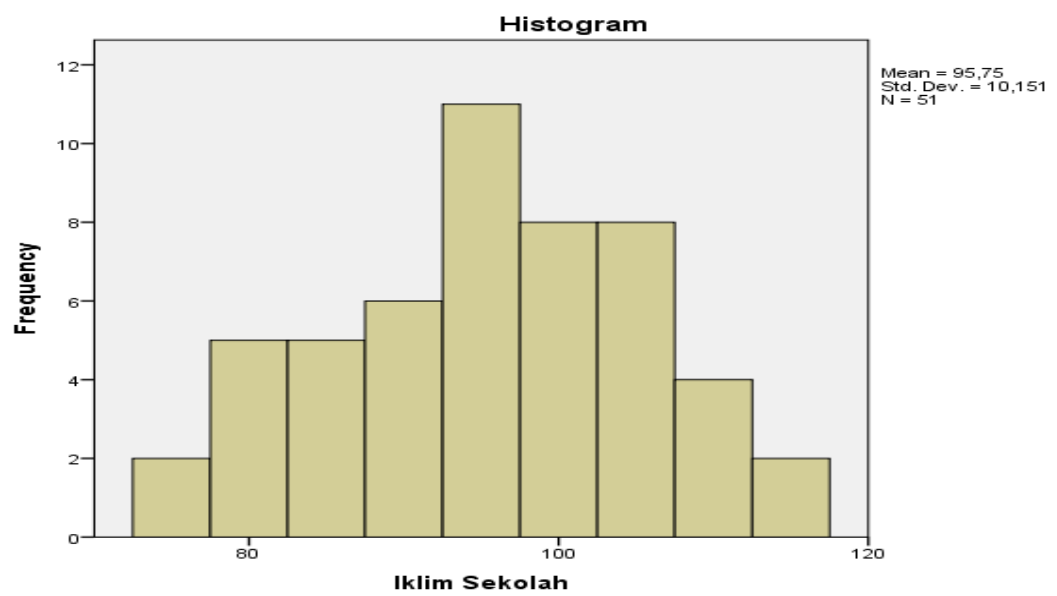

Distribusi frekkuensi tentang iklim sekolah

\begin{tabular}{|c|c|c|c|}
\hline Interval & Kategori & Frekuensi & Presentase $(\%)$ \\
\hline$\geq 103$ & Tinggi & 19 & 37,26 \\
\hline $89-103$ & Sedang & 27 & 52,94 \\
\hline$\leq 89$ & Rendah & 5 & 9,80 \\
\hline \multicolumn{2}{|c|}{ Jumlah } & 51 & 100 \\
\hline
\end{tabular}




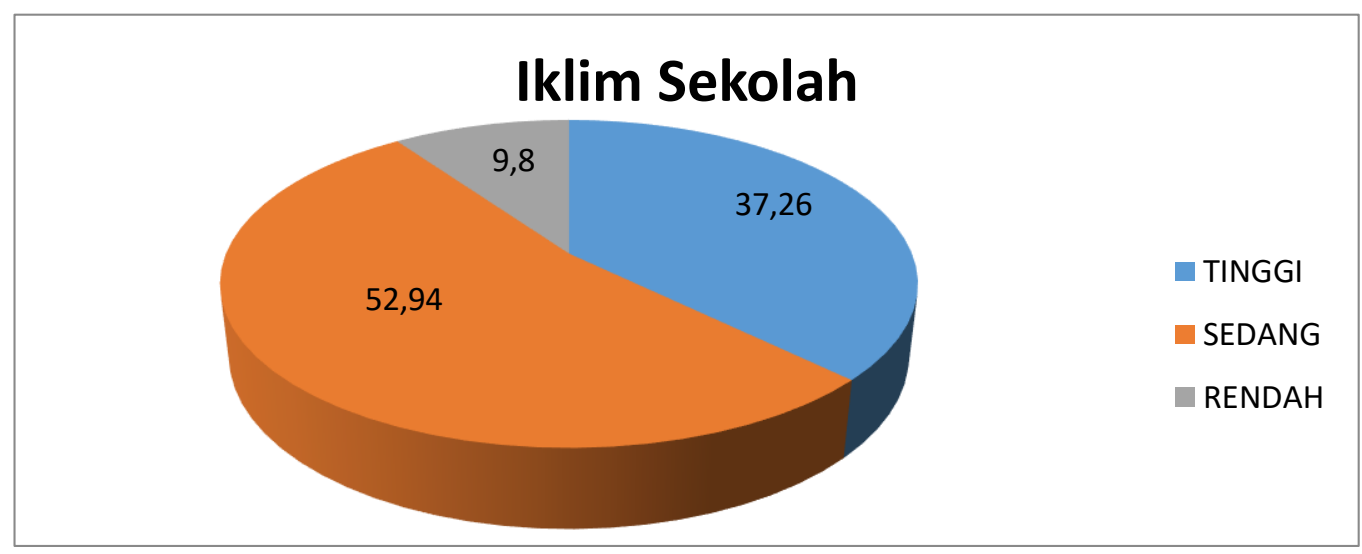

Gambar Diagram Lingkaran

Data deskripsi yang diperoleh dari angket Kenerja Guru terdiri dari 30 butir pernyataan yang telah diisi oleh responden terlihat pada tabel 12 berikut.

Tabel 12 hasil analisis deskripsi Kenerja Guru

\begin{tabular}{cc}
\hline Statistika Deskriptif & Nilai Statistik \\
\hline Rata-rata & 96,02 \\
Median & 95,00 \\
Modus & 94 dan 101 \\
Standar Deviasi & 10,975 \\
Kurtosis & $-0,696$ \\
Skewness & $-0,063$ \\
Rentang & 43 \\
Minimum & 75 \\
Maksimum & 118 \\
Jumlah & 51 \\
\hline
\end{tabular}

Sumber : Hasil analisis data primer (2021)

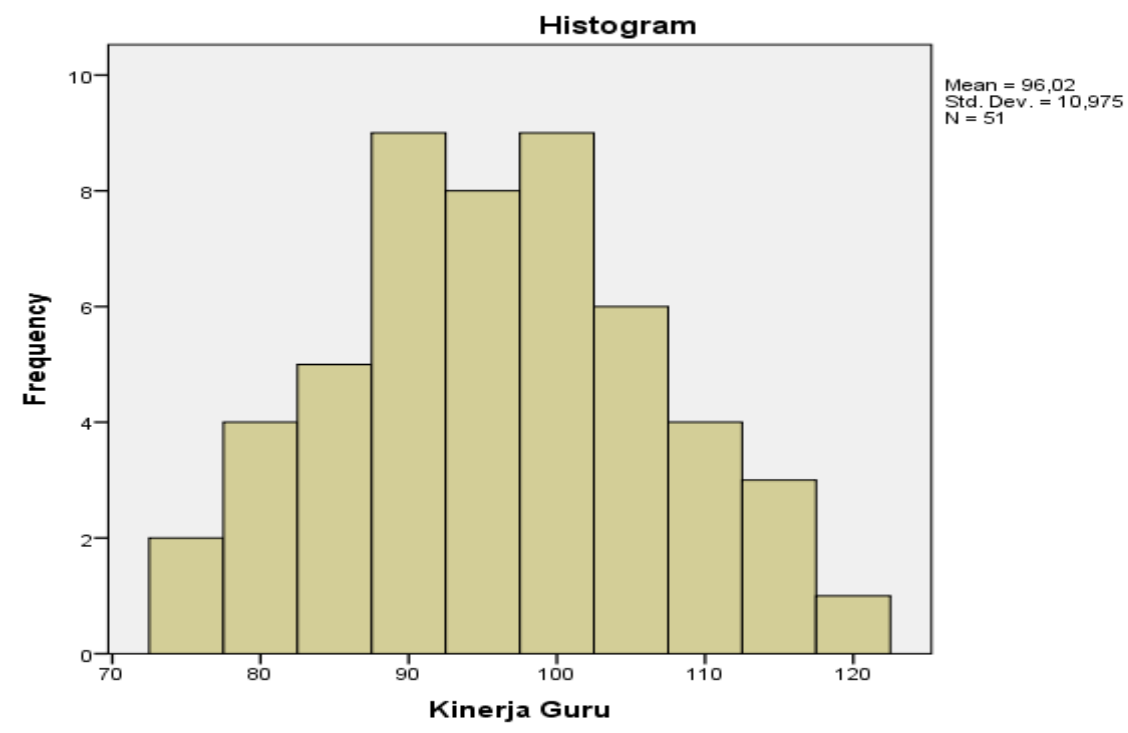


Distribusi frekkuensi tentang kinerja guru

\begin{tabular}{|c|c|c|c|}
\hline Interval & Kategori & Frekuensi & Presentase (\%) \\
\hline$\geq 103,67$ & Tinggi & 16 & 31,38 \\
\hline $89,33-103,67$ & Sedang & 30 & 58,82 \\
\hline$\leq 89,33$ & Rendah & 5 & 9,80 \\
\hline \multicolumn{2}{|c|}{ Jumlah } & 51 & 100 \\
\hline
\end{tabular}

Sumber: Hasil analisis data primer (2021)

\section{Motivasi Kerja}

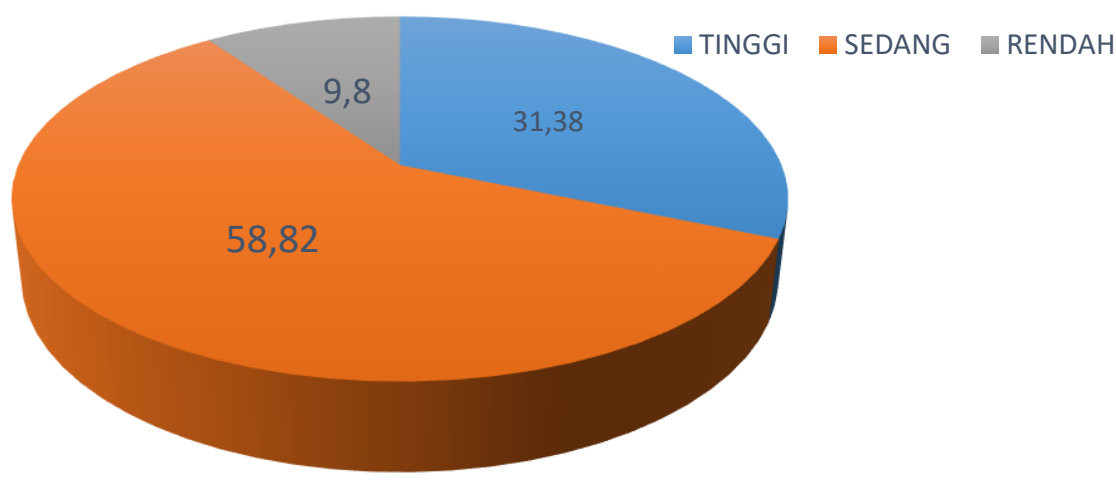

Diagram lingkaran kenerja guru

\section{Hasil Uji Prasyarat Analisis}

\section{a. Uji Normalitas Data}

Hasil Uji Normalitas Data Kolmogorov-Smirnov

\begin{tabular}{lllll}
\hline & \multicolumn{2}{l}{ Kolmogorov-Smirnov $^{a}$} & \multicolumn{2}{l}{ Shapiro-Wilk } \\
\cline { 2 - 5 } & Statistik & Sig & Statistik & Sig \\
\hline Iklim Sekolah & 0,098 & 0,200 & 0,987 & 0,614 \\
Kinerja Guru & 0,066 & 0,200 & 0,982 & 0,622 \\
\hline
\end{tabular}

Sumber: Hasil analisis data primer (2021)

\section{b. Uji Linearitas Data}

Hasil Uji Linieritas Data (Test for Linierity) X terhadap Y

\begin{tabular}{|c|c|c|c|c|c|c|c|}
\hline & & & $\begin{array}{l}\text { Sum of } \\
\text { Squeres }\end{array}$ & $d f$ & $\begin{array}{l}\text { Mean } \\
\text { Square }\end{array}$ & $F$ & Sig \\
\hline \multirow[t]{5}{*}{$\begin{array}{l}\text { Kinerja Guru* } \\
\text { Iklim Sekolah }\end{array}$} & $\begin{array}{l}\text { Between } \\
\text { Groups }\end{array}$ & (Combinet) & 5036,647 & 27 & 186,542 & 4,350 & 0,000 \\
\hline & & Linearity & 3528,037 & 1 & 3528,037 & 82,269 & 0,000 \\
\hline & & Deviation $f l$ & 1508,610 & 26 & 58,023 & 1,353 & 0,234 \\
\hline & $\begin{array}{l}\text { Within } \\
\text { Group }\end{array}$ & & 986,333 & 23 & 43,884 & & \\
\hline & Total & & 6022,980 & 51 & & & \\
\hline
\end{tabular}

Sumber: Hasil analisis data primer (2021) 


\section{c. Uji Multikolinearitas}

Hasil Uji Multikolinearitas

\begin{tabular}{|c|c|c|c|c|c|c|c|c|}
\hline \multirow[b]{2}{*}{ Model } & & \multicolumn{2}{|c|}{$\begin{array}{l}\text { Unstandardized } \\
\text { Coefficients }\end{array}$} & $\begin{array}{l}\text { Standardized } \\
\text { Coefficients }\end{array}$ & & & \multicolumn{2}{|c|}{$\begin{array}{l}\text { Collinearity } \\
\text { Statistics }\end{array}$} \\
\hline & & $\mathrm{B}$ & $\begin{array}{l}\text { Std. } \\
\text { Error }\end{array}$ & Beta & $\mathrm{t}$ & Sig & $\begin{array}{c}\text { Tolera } \\
\text { nce }\end{array}$ & VIF \\
\hline \multirow[t]{3}{*}{1} & (constant) & 0,592 & 7,914 & & 0,075 & 0,941 & & \\
\hline & Iklim & $-0,173$ & 0,189 & $-0,160$ & - & 0,363 & 0,167 & 6,006 \\
\hline & Sekolah & & & & 0.919 & & & \\
\hline
\end{tabular}

a. Dependent Variabel: Kinerja Guru

Sumber: Hasil analisis data primer (2021)

\section{Hasil Analisis Data}

simultan dan parsial. Berikut tabel analisis regresi

Analisis Regresi

\begin{tabular}{llcc}
\hline Model & & \multicolumn{2}{c}{ Unstandardized Coefficients } \\
\cline { 3 - 4 } & & $\mathrm{B}$ & Std. Error \\
\hline 1 & (constant) & 0,592 & 7,914 \\
& Iklim Sekolah & $-0,173$ & 0,189 \\
& Motivasi Kerja & 1,171 & 0,201 \\
\hline
\end{tabular}
a. Dependent Variabel: Kinerja Guru
b. Sumber: Hasil analisis data primer (2021)
c. Dari persamaan regresi berganda diperoleh sebagai berikut:
d. $\hat{Y}=\beta 0+\beta 1 X 1+\beta 2 X_{2}$
e. $\hat{Y}=0,592+(-0,173 \mathrm{X} 1)+(1,171 \mathrm{X} 2)$

\section{Pengujian Hipotesis}

\section{a. Uji Parsial (Uji t)}

Hasil uji parsial variabel iklim sekolah

\begin{tabular}{llrrrrr}
\hline Model & & $\begin{array}{l}\text { Sum of } \\
\text { Squares }\end{array}$ & $d f$ & $\begin{array}{l}\text { Mean } \\
\text { Square }\end{array}$ & $F$ & Sig \\
\hline 1 & Regression & 3528,037 & 1 & 3528,037 & 69,290 & $0,000^{\mathrm{b}}$ \\
& Residual & 2494,943 & 49 & 50,917 & & \\
& Total & 6022,980 & 50 & & & \\
\hline
\end{tabular}

a. Dependent Variable: Kinerja Guru

b. Predictors: (Constant): Iklim Sekolah

Sumber: Hasil analisis data primer (2021)

\section{c. Uji Determinasi $\left(\mathbf{R}^{2}\right)$}

Koefisien determinasi secara simultan

\begin{tabular}{lcccc}
\hline Model & $R$ & $R$ Square & $\begin{array}{c}\text { Afjusted } R \\
\text { Square }\end{array}$ & $\begin{array}{c}\text { Std Error of } \\
\text { the Estimate }\end{array}$ \\
\hline 1 & $0,870^{\mathrm{a}}$ & 0,757 & 0,747 & 5,523 \\
\hline
\end{tabular}

a. Predictors: (Constant), Motivasi Kerja, Iklim Sekolah 
b. Dependent Variable: Kinerja Guru

Sumber: Hasil analisis data primer (2021)

Koefisien determinasi secara parsial $\left(\mathrm{X}_{1}\right)$ terhadap $(\mathrm{Y})$

\begin{tabular}{lcccc}
\hline Model & $R$ & $R$ Square & $\begin{array}{c}\text { Afjusted } R \\
\text { Square }\end{array}$ & $\begin{array}{c}\text { Std Error of } \\
\text { the Estimate }\end{array}$ \\
\hline 1 & $0,765^{\text {a }}$ & 0,586 & 0,577 & 7,136
\end{tabular}

a. Predictors: (Constant), Iklim Sekolah

b. Dependent Variable: Kinerja Guru

Tabel 24. Koefisien determinasi secara parsial $\left(\mathrm{X}_{2}\right)$ terhadap $(\mathrm{Y})$

\begin{tabular}{ccccc}
\hline & & & Afjusted $R$ & $\begin{array}{c}\text { Std Error of } \\
\text { Model }\end{array}$ \\
& $R$ & $R$ Square & Square & thestimate \\
\hline 1 & $0,868^{\mathrm{a}}$ & 0,753 & 0,748 & 5,514 \\
\hline
\end{tabular}

a. Predictors: (Constant), Motivasi Kerja

b. Dependent Variable: Kinerja Guru

\section{Pembahasan}

\section{Deskripsi iklim sekolah di UPT SD Negeri di Kecamatan Sukamaju.}

Berdasarkan hasil diperoleh data skor variabel iklim sekolah $\left(\mathrm{X}_{1}\right)$ UPT Sekolah Dasar Negeri di Kecamatan Sukamaju terdapat 5 responden $(9,80 \%)$ berada pada kategori rendah, 27 responden (52,94\%) pada kategori sedang dan 19 responden $(37,26 \%)$ berada pada kategori tinggi. Dikaitkan dengan tabel 8, skor rata-rata variabel iklim sekolah 95,75 berada pada interval (89-103) dengan kategori sedang. Dengan demikian dapat dikatakan bahwa skor variabel iklim sekolah $\left(\mathrm{X}_{1}\right)$ termasuk kategori sedang. Diagram lingkaran gambar 3 menunjukkan bahwa iklim sekolah cukup bagus karena 37,26\% berada pada kategori tinggi, sedangkan kategori sedang sebesar 52,94\% dengan kategori rendah berada pada 9,80\%, artinya iklim sekolah di kecamatan sukamaju sudah berada di kategori sedang.

\section{Deskripsi kinerja guru dalam pembelajaran matematika di UPT SD} Negeri di Kecamatan Sukamaju

Berdasarkan tabel 13 diperoleh data skor variabel kenerja guru dalam pembelajaran matematika (Y) UPT Sekolah Dasar Negeri di Kecamatan Sukamaju terdapat 5 responden $(9,80 \%)$ berada pada kategori rendah, 30 responden $(58,82 \%)$ kategori sedang dan 16 responden $(31,38 \%)$ berada pada kategori tinggi. Dikaitkan dengan tabel 13, skor rata-rata variabel motivasi kerja 96,02 berada pada interval $(89,33-103,67)$ dengan kategori sedang dan median 95,00. Dengan demikian dapat dikatakan bahwa skor variabel kenerja guru dalam pembelajaran matematika(Y) termasuk kategori sedang 


\section{Pengaruh iklim sekolah terhadap kinerja guru dalam pembelajaran Matematika di UPT SD Negeri di Kecamatan Sukamaju}

Hasil analisis regresi menunjukkan bahwa angka koefisien korelasi (R) sebesar 0,765 berada pada rentang $(0,60-, 799)$ kategori kuat. Hasil ini menunjukkan bahwa terjadi hubungan yang kuat antara iklim sekolah terhadap kinerja guru dalam pembelajaran matematika di UPT Sekolah Dasar Negeri di Kecamatan Sukamaju. Koefisien determinasi $\left(\mathrm{R}^{2}\right)$ sebesar 0,586 atau 58,6\%. Sehingga dapat dikatakan bahwa pengaruh iklim sekolah terhadap kinerja guru dalam pembelajaran matematika di UPT Sekolah Dasar Negeri di Kecamatan Sukamaju berkontribusi $58,6 \%$.

\section{Kesimpulan}

Berdasarkan hasil analisis data penelitian dan pengujian hipotesis pada Bab IV, maka dapat disimpulkan bahwa iklim sekolah dapat mempengaruhi kinerja guru dalam pembelajaran matematika di UPT Sekolah Dasar Negeri di Kecamatan Sukamaju. Secara rinci dinyatakan sebagai berikut:

1. Hasil analisis deskripsi menunjukkan bahwa rata-rata iklim sekolah 95,75 berada pada interval ( 89-103) dengan kategori sedang. Sehingga dapat dikatakan bahwa iklim sekolah yang ada di UPT Sekolah Dasar Negeri di Kecamatan Sukamaju berada pada kategori sedang.

2. Gambaran kinerja guru dalam pembelajaran matematika di UPT Sekolah Dasar Negeri di Kecamatan Sukamaju pada kategori sedang dengan rata-rata skor 96,02 beada pada interval ( 89 - 103) kategori sedang.

3. Pengaruh positif iklim sekolah terhadap kinerja guru dalam pembelajaran matematikan di UPT Sekolah Dasar Negeri di Kecamatan Sukamaju adalah sebesar $58,6 \%$. 


\section{Daftar Pustaka}

Ariani D, 2020, Pengaruh Disiplin Kerja, Iklim Organisasi dan Komitmen Urganisasi terhadap Produktivitas Kerja Guru, Jakarta : Universitas Mercu Buana Jakarta.

Arikunto, Suharsini 1998, Prosedur Penelitian Suatu Pendekatan Praktik, Edisi Revisi IV, Cetakan ke II, Jakarta : RineKa Cipta.

Asmawati E, 2020, Pengaruh Supervisi Akademik Kepala Sekolah terhadap Kinerja Mengajar Guru, Purwakatra : Jurnal Manajemen Pendidikan Islam.

Fadhilah MLZ, 2020, Pengaruh Gaya Kepemimpinan Transformasional Kepala Sekolah Terhadap Etos Kerja Guru dan Staf, Bandung : Universitas Pendidikan Indonesia.

Gusman HE, 2014, Hubungan Gaya Kepemimpinan Kepala Sekolah dengan Kinerja Guru di SMP N Kecamatan Palembayan Kabupaten Agam, Agam : FIP UNP.

Hasibuan RS, 2013, Iklim Komunikasi Organisasi dalam Menumbuhkan Motivasi Kerja dan Kesejahteraan Guru di Pesantren Modern Daar Al Uluum Kisaran Kabupaten Asahan, Asahan : Sekolah Tinggi Agama Islam Negeri Mandailing Natal

Ideswal, Yahya, Alkadri H, 2020, Kontribusi Iklim Sekolah dan Kepemimpinan Kepala Sekolah terhadap Kinerja Guru Sekolah Dasar, Sumatera Barat : Universitas Negeri Padang.

Muhson, Ali, 2012, Pelatihan Analisis Statistik dengan SPSS, Yogyakarta: Fakultas Ekonomi Universitas Negeri Yogyakarta.

Murwani S, 2019, Pengaruh Peran Kepala Sekolah dan Kepuasan Kerja terhadap Kinerja Guru SMP/MTs di Kecamatan Susukan Kabupaten Semarang, Semarang : Jurnal Manajemen Pendidikan.

Nur RF, 2020, Kontribusi Kepala Sekolah dalam Meningkatkan Kinerja dan Profesionalisme Guru di MAN Kota Palu, Palu : Institut Agama Islam Negeri (IAIN) Datokarama Palu.

Putri A, 2019, Implementasi Kepemimpinan Kepala Sekolah, Iklim Sekolah dan Kunci Sukses Kepala Sekolah, Padang : Universitas Negeri Padang.

Putri AP, 2015, Kontribusi Iklim Kerja terhadap Kreativitas Guru Sekolah Dasar Negeri Kecamatan Tanjung Harapan Kota Solok, Solok : Jurusan Administrasi Pendidikan FIP UNP. 
Rifa'i AA, 2020, Pengaruh Kepemimpinan Transformasional Kepala Sekolah dan Budaya Kerja terhadap Peningkatan Kinerja Guru, Ciamis : Universitas Galuh Jawa Barat Indonesia.

Salam A, 2020, Hubungan antara Motivasi Kerja dan Kualitas Kekaryaan dengan Kinerja Guru SMA Swasta di Kabupaten Pangkajene dan Kepulauan, Pangkep : Sekolah Menegah Atas (SMA) Negeri 20 Pangkep, Indonesia.

Sanjaya S, 2017, pengaruh Kecerdasan Emosional, Perkataan Orang Tua, dan Kebiasaan belajar matematika terhadap prestasi belajar matematika siswa, SMKN I Tomoni: (Tesis UNCP)

Sawianti I, 2019, Pengaruh Iklim Sekolah terhadap Kinerja Guru di SMP Negeri 1 Ulaweng Kabupaten Bone, Makassar : Universitas Islam Negeri Alauddin Makassar.

Soemanto, Wasty, 2014, Psikologi Pendidikan, Jakarta : PT RineKa Cipta.

Sugiyono, 2013, Metode Penelitian Pendidikan, Bandung: CV Alfabeta

Sumarnie, 2017, Pengaruh Kepemimpinan Kepala Sekolah dan Motivasi Kerja terhadap Kinerja Guru Sekolah Menengah Pertama (SMP) Negeri 8 Kota Palngka Raya, Palangka Raya : FKIP UPR

Utami ST, 2016, Pengaruh Iklim Sekolah terhadap Kinerja Guru di MTs seKecamatan Kemranjen, Banyumas, Purwokerto : Fakultas Tarabiah dan Ilmu Keguruan IAIA Purwokerto.

Widuri VS, 2020, Pengaruh Disiplin Kerja, Motivasi Kerja, dan Budaya Organisasi terhadap Kinerja, Jakarta : Universitas Pelita Harapan Indonesia.

Yaman A, 2020, Pengaruh Kepemimpinan Kepala Sekolah, Tunjangan Profesi Guru, dan Iklim Sekolah terhadap Kinerja Guru SMK Negeri di Kota Makassar, Makassar : Universitas Islam Negeri Alauddin Makassar. Indonesia. 